\title{
Engineering of a Microbial Cell Factory for the Extracellular Production of Catalytically Active Phospholipase $A_{2}$ of Streptomyces violaceoruber
}

\author{
Hyun-Jae Lee ${ }^{1 \dagger}$, Ara Cho ${ }^{2 \dagger}$, Yeji Hwang ${ }^{2}$, Jin-Byung Park ${ }^{2 *}$, and Sun-Ki Kim ${ }^{1 *}$ \\ ${ }^{1}$ Department of Food Science and Technology, Chung-Ang University, Anseong, Gyeonggi 17546, Republic of Korea \\ ${ }^{2}$ Department of Food Science and Engineering, Ewha Womans University, Seoul 03760, Republic of Korea
}

Phospholipase $A_{2}\left(P L A_{2}\right)$ from Streptomyces violaceoruber is a lipolytic enzyme used in a wide range of industrial applications including production of lysolecithins and enzymatic degumming of edible oils. We have therefore investigated expression and secretion of PLA in two workhorse microbes, Pichia pastoris and Escherichia coli. The $\mathrm{PLA}_{2}$ was produced to an activity of $0.517 \pm 0.012 \mathrm{U} / \mathrm{ml}$ in the culture broth of the recombinant $P$. pastoris. On the other hand, recombinant E. coli BL21 star (DE3), overexpressing the authentic PLA $\left(P-P L A_{2}\right)$, showed activity of $17.0 \pm 1.3 \mathrm{U} / \mathrm{ml}$ in the intracellular fraction and $21.7 \pm 0.7 \mathrm{U} / \mathrm{ml}$ in the culture broth. The extracellular PLA $A_{2}$ activity obtained with the recombinant $E$. coli system was 3.2-fold higher than the corresponding value reached in a previous study, which employed recombinant E. coli BL21 (DE3) overexpressing codon-optimized PLA ${ }_{2}$. Finally, we observed that the extracellular $\mathrm{PLA}_{2}$ from the recombinant $E$. coli P-PLA ${ }_{2}$ culture was able to hydrolyze $31.1 \mathrm{~g} / \mathrm{l}$ of crude soybean lecithin, an industrial substrate, to a conversion yield of approximately $95 \%$. The newly developed $E$. coli-based $\mathrm{PLA}_{2}$ expression system led to extracellular production of PLA ${ }_{2}$ to a productivity of $678 \mathrm{U} / / \cdot h$, corresponding to 157-fold higher than that obtained with the $P$. pastoris-based system. This study will contribute to the extracellular production of a catalytically active PLA . $_{\text {. }}$

Keywords: Phospholipase $A_{2}$, Pichia pastoris, Escherichia coli, extracellular production

Received: January 30, 2020 Accepted: February 28, 2020 First published online: March 02, 2020

*Corresponding authors S.K.K.

Phone: 82-31-670-3261 Fax: +82-31-675-3108 E-mail: skkim18@cau.ac.kr J.B.P.

Phone: +82-2-3277-4509 Fax: $+82-2-3277-4213$ E-mail: jbpark06@ewha.ac.kr

${ }^{\dagger}$ These authors contributed equally to this work.

Supplementary data for this paper are available on-line only at http://jmb.or.kr.

pISSN 1017-7825 elSSN 1738-8872

Copyright(C) 2020 by The Korean Society for Microbiology and Biotechnology

\section{Introduction}

Phospholipase $\mathrm{A}_{2}\left(\mathrm{PLA}_{2}, \mathrm{EC} 3.1 .1 .4\right)$ hydrolyzes the ester bond in the sn-2 position of phospholipids, producing free fatty acids and the corresponding lysophospholipids. In comparison with native lecithins, lysolecithins prepared by $\mathrm{PLA}_{2}$ not only exhibit enhanced $\mathrm{O} / \mathrm{W}$ emulsifying properties but also form stable emulsions under various process conditions [1]. Thus, lysolecithins are used in a wide range of industrial applications such as food, cosmetics, and pharmaceuticals [2]. In particular, PLA $_{2}$ can be used extensively for enzymatic degumming, a key process in the refining of vegetable and other edible oils [3].

Previous studies have been mainly focused on expression and characterization of eukaryotic secretory PLA $\mathrm{P}_{2} \mathrm{~s}$. While eukaryotic $\mathrm{PLA}_{2}$ s have been successfully expressed in yeast [4-7] and fungus [8], inclusion bodies were formed when expressed in Escherichia coli due to the presence of five to eight disulfide bonds [9, 10]. Nevertheless, it would be desirable to establish an E. coli-based $\mathrm{PLA}_{2}$ expression system because eukaryotic systems are generally considered as time consuming and uneconomic in comparison to prokaryotic systems. For this reason, several research groups developed expression systems for soluble expression of the eukaryotic $\mathrm{PLA}_{2}$ in E. coli using maltose-binding protein (MBP) [11], thioredoxin [12], and protein disulfide bond isomerase (DsbC) [13] as fusion partners. These expression systems, however, require additional steps to eliminate fusion partners and hence are not economic for practical use [14].

It has been relatively easy to express prokaryotic $\mathrm{PLA}_{2}$ in $E$. coli because it has only two or zero disulfide bonds [15]. The first $\mathrm{PLA}_{2}$ identified in prokaryotes was from Streptomyces violaceoruber A-2688, a soil bacterium [16]. It is a small protein with molecular weight of $14 \mathrm{kDa}$ containing two disulfide bonds and requires $\mathrm{Ca}^{2+}$ for catalytic activity. The PLA $\mathrm{P}_{2}$ from $S$. violaceoruber was successfully produced extracellularly by $P$. pastoris [17] and E. coli [18]. The $\mathrm{PLA}_{2}$ expressed in P. pastoris, however, contains a part of its signal sequence at the N-terminal end of mature $\mathrm{PLA}_{2}$ protein, which might alter properties of the authentic PLA ${ }_{2}$.

In this study, expression and secretion levels of the authentic PLA $\mathrm{P}_{2}$ in P. pastoris and E. coli were compared. Since the amount of extracellular PLA $_{2}$ produced in E. coli was 8.4 times higher than that in P. pastoris, we sought to develop an efficient $\mathrm{PLA}_{2}$ expression system in E. coli. To do so, effects of the following factors on extracellular 
production of $\mathrm{PLA}_{2}$ were systematically investigated: (1) codon optimization, (2) various host strains, and (3) attachment of aspartate tags.

\section{Materials and Methods}

\section{Strains and Plasmids}

E. coli TOP10 strain was used for genetic manipulation, and P. pastoris X-33, E. coli BL21 star (DE3), Origami 2 (DE3), BL21 (DE3), BL21 RIL (DE3), C41 (DE3), and C43 (DE3) strains were used for PLA 2 production. For expression of $\mathrm{PLA}_{2}$ in $P$. pastoris, codon-optimized $\mathrm{PLA}_{2}$ gene was cloned behind the $A O X 1$ promoter in plasmid $\mathrm{pPICZ} \alpha \mathrm{A}$ and their transcription was induced by adding methanol. Codon optimization was carried out by using the program (https://zendto.bioneer.co.kr/codon/index.py) provided by Bioneer (Korea). For expression of PLA in E. coli, the natural and codon-optimized $\mathrm{PLA}_{2}$ genes were located behind the T7 promoter in plasmid pET$26 \mathrm{~b}(+)$ and their transcription was induced by adding isopropyl- $\beta$-D-thiogalactopyranoside (IPTG). The natural and codon-optimized PLA 2 genes were synthesized by Bioneer. Strains and plasmids used in this study are listed in Table 1.

\section{Genetic Manipulation}

The natural PLA $\mathrm{A}_{2}$ or codon-optimized $\mathrm{PLA}_{2}$ genes without native signal sequence (Fig. S1) were PCR amplified with primers of HL01 (with MscI site) and HL02 (with XhoI site) or HL03 (with MscI site) and HL04 (with XhoI

Table 1. Strains and plasmids used in this study.

\begin{tabular}{|c|c|c|}
\hline Name & Description & Reference \\
\hline \multicolumn{3}{|l|}{ E. coli } \\
\hline E. coli TOP10 & $\begin{array}{l}\mathrm{F}^{-} \text {mcrA } \Delta(\text { mrr-hsdRMS-mcrBC) } \Phi 80 \text { lacZ } \Delta M 15 \Delta \text { lacX74 recA1 araD139 } \Delta \text { (ara- } \\
\text { leu)7697 galU galK } r p s L\left(\operatorname{Str}^{\mathrm{R}}\right) \text { endA1 nupG }\end{array}$ & Invitrogen \\
\hline E. coli BL21 (DE3) & F' ompT hsdS (rB- mB-) dcm gal (DE3 [lacI lacUV5-T7 gene 1 ind1 sam7 nin5]) & $\begin{array}{l}\text { Novagen } \\
\text { (Darmstadt, Germany) }\end{array}$ \\
\hline $\begin{array}{l}\text { E. coli BL21 star } \\
\text { (DE3) }\end{array}$ & BL21 rne131 (DE3) & Invitrogen \\
\hline $\begin{array}{l}\text { E. coli BL21 } \\
\text { CodonPlus-RIL } \\
\text { (DE3) }\end{array}$ & BL21 (DE3) $d_{c m}^{+}$Tet $^{\mathrm{R}}$ endA Hte $\left[\arg U\right.$ ileY leuW $\left.\mathrm{Cam}_{\mathrm{R}}\right]$ & Agilent technologies \\
\hline E. coli C41 (DE3) & BL21 (DE3 [lacI lac-T7 gene 1 ind1 sam7 nin5]) & $\begin{array}{l}\text { Lucigen } \\
\text { (Middleton, WI, USA) }\end{array}$ \\
\hline E. coli C43 (DE3) & C41 (DE3) derivative & Lucigen \\
\hline $\begin{array}{l}\text { E. coli Origami } 2 \\
\text { (DE3) }\end{array}$ & 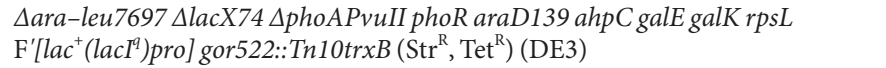 & Novagen \\
\hline SK33 & BL21 star $(\mathrm{DE} 3)$ containing pET-26b $(+)$ & This study \\
\hline SK31 & BL21 star (DE3) containing pHLK01 & This study \\
\hline SK32 & BL21 star (DE3) containing pHLK02 & This study \\
\hline SK35 & Origami 2 (DE3) containing pHLK01 & This study \\
\hline SK36 & BL21 (DE3) containing pHLK01 & This study \\
\hline SK37 & BL21 RIL (DE3) containing pHLK01 & This study \\
\hline SK38 & C41 (DE3) containing pHLK01 & This study \\
\hline SK39 & C43 (DE3) containing pHLK01 & This study \\
\hline SK54 & BL21 star (DE3) containing pHLK03 & This study \\
\hline SK55 & BL21 star (DE3) containing pHLK04 & This study \\
\hline SK56 & BL21 star(DE3) containing pHLK05 & This study \\
\hline SK57 & BL21 star(DE3) containing pHLK06 & This study \\
\hline SK87 & BL21 star(DE3) containing pSHK01 & This study \\
\hline \multicolumn{3}{|l|}{ P. pastoris } \\
\hline P. pastoris $\mathrm{X}-33$ & Wild type & Invitrogen \\
\hline $\mathrm{PX}$ & $\mathrm{X}-33$ containing pPICZaA & This study \\
\hline $\mathrm{PP}$ & $\mathrm{X}-33$ containing $\mathrm{pMF} \alpha-\mathrm{PLA}_{2}$ & This study \\
\hline \multicolumn{3}{|l|}{ Plasmids } \\
\hline pET-26b(+) & pBR322 origin, $T 7$ promoter, PelB signal sequence, His-tag, $\operatorname{Kan}^{\mathrm{R}}$ & Novagen \\
\hline pHLK01 & Expression vector containing P-PLA ${ }_{2}, \operatorname{Kan}^{\mathrm{R}}$ & This study \\
\hline pHLK02 & Expression vector containing P-Opt. $\mathrm{PLA}_{2}, \mathrm{Kan}^{\mathrm{R}}$ & This study \\
\hline pHLK03 & Expression vector containing P-D3-PLA ${ }_{2}, \mathrm{Kan}^{\mathrm{R}}$ & This study \\
\hline pHLK04 & Expression vector containing P-D5-PLA $2, \operatorname{Kan}^{\mathrm{R}}$ & This study \\
\hline pHLK05 & Expression vector containing P-D7-PLA ${ }_{2}, \operatorname{Kan}^{\mathrm{R}}$ & This study \\
\hline pHLK06 & Expression vector containing P-D9-PLA $2, \mathrm{Kan}^{\mathrm{R}}$ & This study \\
\hline pSHK01 & Expression vector containing $\mathrm{PLA}_{2}, \mathrm{Kan}^{\mathrm{R}}$ & This study \\
\hline pPICZaA & pUC origin, $A O X 1$ promoter, MFa signal sequence, His-tag, Zeocin ${ }^{\mathrm{R}}$ & Invitrogen \\
\hline pMFa-PLA 2 & Expression vector containing M-Opt. PLA $2, Z_{e o c i n}{ }^{R}$ & This study \\
\hline
\end{tabular}


site). After the gene amplification, PCR products were cut with $M s c \mathrm{I}$ and $\mathrm{XhoI}$ and then ligated with plasmid pET$26 \mathrm{~b}(+)$ digested with the same enzymes to construct pHLK01 and pHLK02 (Table 1). To attach various lengths of aspartate residues at the $\mathrm{N}$-terminal end of $\mathrm{PLA}_{2}$, plasmid pHLK01 was amplified with the primer sets and then ligated after MscI treatment. The primer sets used for amplification of the DNA fragments are as follows: HL07 (with MscI site) and HL11 (with MscI site) for pHLK03; HL08 (with MscI site) and HL11 (with MscI site) for pHLK04; HL09 (with MscI site) and HL11 (with MscI site) for pHLK05; HL10 (with MscI site) and HL11 (with MscI site) for pHLK06. Plasmid pSHK01 is identical to pHLK01 except that it does not contain the PelB signal sequence. To make this change, a DNA fragment without PelB signal sequence was amplified with primers $\mathrm{SH} 05$ (with NdeI site) and SH06 (with NdeI site) using pHLK01 as template. This linear DNA was digested with NdeI and ligated to construct pSHK01.

The codon-optimized PLA 2 gene for expression in P. pastoris was PCR-amplified with primers F_PLA (with NheI site) and R_PLA 2 (with SpeI site). The plasmid pPICZaA was amplified with primers F_pPICZaA (with NheI site) and R_pPICZaA (with SpeI site). These two linear DNA fragments were digested with NheI and SpeI, and ligated to construct $\mathrm{pMF} \alpha-\mathrm{PLA}_{2}$. Transformation of the cassette for overexpressing $\mathrm{PLA}_{2}$ was performed using the Pichia EasyComp Kit (Invitrogen, USA). Plasmid pMFa-PLA ${ }_{2}$ was cut with MssI and transformed. Transformants were selected on YPDS medium ( $10 \mathrm{~g} / \mathrm{l}$ yeast extract, $20 \mathrm{~g} / \mathrm{l}$ peptone, $20 \mathrm{~g} / \mathrm{lglucose}$, and $182 \mathrm{~g} / \mathrm{l}$ sorbitol) containing $100 \mu \mathrm{g} / \mathrm{ml}$ Zeocin. PCR amplification was done with primers (F_ch_AOX1p and R_ch_pPICZ $\alpha$ ) to verify positive transformants. All plasmids and the check PCR products were sequenced by automatic sequencing (Cosmogenetech, Korea). Names of recombinant $\mathrm{PLA}_{2}$ gene products and schematic structures are shown in Fig. 1, and primers used for plasmid constructions and confirmations are listed in Table S1.

\section{Media and Culture Conditions}

P. pastoris was pre-cultured in $100 \mathrm{ml}$ BMGY medium $(10 \mathrm{~g} / \mathrm{l}$ yeast extract, $20 \mathrm{~g} / \mathrm{l}$ peptone, $13.4 \mathrm{~g} / \mathrm{l}$ yeast nitrogen base, $3 \times 10^{-4} \mathrm{~g} / \mathrm{l}$ biotin, $10 \mathrm{~g} / \mathrm{l}$ glycerol, and $100 \mathrm{mM}$ potassium phosphate $(\mathrm{pH} 6.0)$ ) at $30^{\circ} \mathrm{C}$ and $200 \mathrm{rpm}$ for $24 \mathrm{~h}$. Pre-cultured cells were then inoculated into $100 \mathrm{ml} \mathrm{BMMY}$ medium containing $10 \mathrm{~g} / \mathrm{l}$ yeast extract, $20 \mathrm{~g} /$ l peptone, $13.4 \mathrm{~g} / \mathrm{l}$ yeast nitrogen base, $3 \times 10^{-4} \mathrm{~g} / \mathrm{l}$ biotin, 5 or $10 \mathrm{~g} / \mathrm{l}$ methanol, and $100 \mathrm{mM}$ potassium phosphate ( $\mathrm{pH}$ 6.0). Expression of $\mathrm{PLA}_{2}$ was induced by adding methanol every $24 \mathrm{~h}$ at a final concentration of $5 \mathrm{or} 10 \mathrm{~g} / \mathrm{l}$.

E. coli cells were pre-cultured in LB medium ( $5 \mathrm{~g} / \mathrm{l}$ yeast extract and $10 \mathrm{~g} / \mathrm{l}$ bacto-trypton) at $37^{\circ} \mathrm{C}$ and $230 \mathrm{rpm}$ for $12 \mathrm{~h}$. After harvesting the cells, the cell pellets were used for inoculation. Batch fermentations were carried out in a $500 \mathrm{ml}$ baffled flask containing $100 \mathrm{ml}$ of Riesenberg medium $\left[13.5 \mathrm{~g} / \mathrm{l} \mathrm{KH}_{2} \mathrm{PO}_{4}, 4.0 \mathrm{~g} / \mathrm{l}\left(\mathrm{NH}_{4}\right)_{2} \mathrm{HPO}_{4}, 1.7 \mathrm{~g} / \mathrm{l}\right.$ citric acid, $1.4 \mathrm{~g} / 1 \mathrm{MgSO}_{4} \cdot 7 \mathrm{H}_{2} \mathrm{O}, 10 \mathrm{ml} / \mathrm{l}$ trace element solution $\left(10 \mathrm{~g} / \mathrm{l} \mathrm{Fe}\right.$ (III) citrate, $2.25 \mathrm{~g} / \mathrm{l} \mathrm{ZnSO}_{4} \cdot 7 \mathrm{H}_{2} \mathrm{O}, 1.0 \mathrm{~g} / \mathrm{l}$ $\left.\left.\mathrm{CuSO}_{4} \cdot 5 \mathrm{H}_{2} \mathrm{O}, 0.35 \mathrm{~g} / \mathrm{l} \mathrm{MnSO} \mathrm{M}_{4} \cdot \mathrm{H}_{2} \mathrm{O}, 0.23 \mathrm{~g} / \mathrm{l} \mathrm{Na}_{2} \mathrm{~B}_{4} \mathrm{O}_{7} \cdot 10 \mathrm{H}_{2} \mathrm{O}, 0.11 \mathrm{~g} / \mathrm{l}\left(\mathrm{NH}_{4}\right)_{6} \mathrm{Mo}_{7} \mathrm{O}_{24}, 2.0 \mathrm{~g} / \mathrm{l} \mathrm{CaCl} \cdot 2 \mathrm{H}_{2} \mathrm{O}\right), \mathrm{pH} 6.8\right]$ with $20 \mathrm{~g} / \mathrm{l}$ glucose. Agitation speed was maintained at $200 \mathrm{rpm}$. When $\mathrm{OD}_{600}$ reached 0.8-1.2, $0.2 \mathrm{mM}$ IPTG was added to the culture broth. After induction, cultivation was continued at $25^{\circ} \mathrm{C}$ for an additional $24 \mathrm{~h}$.

\section{Preparation of Protein}

After IPTG induction of $24 \mathrm{~h}$, the culture broth was centrifuged at $15,000 \times g$ for 10 min to collect the medium fraction. The remaining pellet was resuspended in B-PER ${ }^{\mathrm{TM}}$ reagent (Thermo Fisher Scientific, USA) and lysed as specified by the manufacturer. The total, soluble, and insoluble fractions of intracellular proteins were prepared as described in the previous report [19].

Cassette M-Opt. PLA

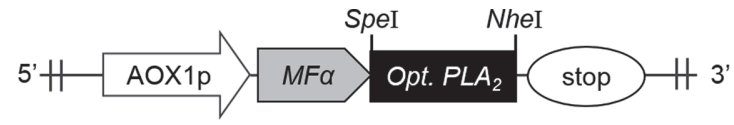

Cassette PLA 2

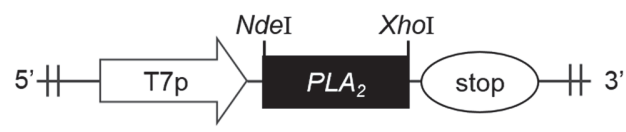

Cassette P-PLA

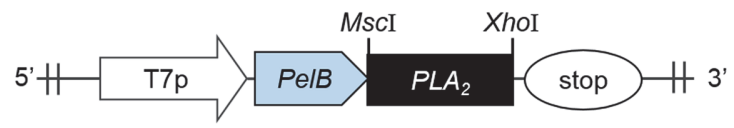

Cassette P-Opt. PLA
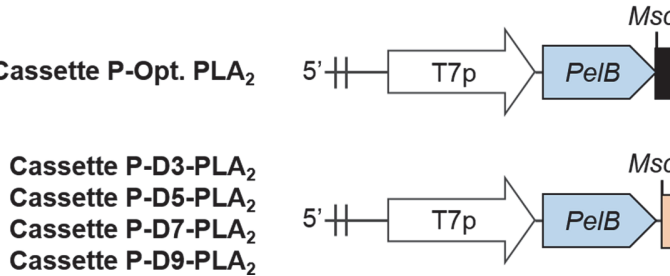

MscI

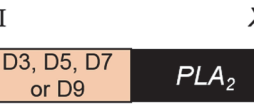

Fig. 1. Schematic diagrams of the structures of recombinant PLA $\mathbf{A}_{2}$ expression cassettes. Symbols: $A O X 1$ promoter (AOX1p), T7 promoter (T7p), translational stop codon (stop), and the genes coding for the signal sequence of $S$. cerevisiae mating factor $\alpha(M F \alpha)$, the signal sequence of pectate lyase B from Erwinia carotovora (PelB), S. violaceoruber phospholipase $\mathrm{A}_{2}\left(\mathrm{PLA}_{2}\right)$, codon-optimized PLA $($ Opt. PLA $)$, 3 aspartates (D3), 5 aspartates (D5), 7 aspartates (D7), and 9 aspartates (D9). 


\section{Protein Purification}

A $20 \mathrm{ml}$-scale column containing $750 \mu \mathrm{l}$ of Ni-NTA agarose (QIAGEN, Germany) was washed with $20 \mathrm{ml}$ of the His-tag binding buffer ( $\mathrm{pH}$ 7.4) containing $20 \mathrm{mM} \mathrm{NaH}_{2} \mathrm{PO}_{4}, 20 \mathrm{mM} \mathrm{Na}_{2} \mathrm{HPO}_{4}, 0.5 \mathrm{M} \mathrm{NaCl}$, and $40 \mathrm{mM}$ imidazole. After $100 \mathrm{ml}$ of the medium fraction prepared as described above was mixed with $300 \mathrm{ml}$ of the His-tag binding buffer, the prepared mixture was loaded into the column. The proteins eluted from the column were collected, and protein concentration was determined using the Bio-Rad protein assay kit with bovine serum albumin (BSA) as the standard.

\section{Analysis of Protein Expression and Enzyme Assay}

To visualize recombinant $\mathrm{PLA}_{2} \mathrm{~s}$, the protein samples were electrophoresed in $12 \%$ sodium dodecyl sulfatepolyacrylamide gel, and were either stained using Coomassie blue or were transferred to a polyvinylidene difluoride (PVDF) membrane (Immobilon-P; EMD Millipore, USA). The membrane was then probed with anti$6 \mathrm{X}$ His tag antibody (abcam, UK). After incubating the membrane with goat F(ab')2 Anti-mouse IgG (abcam) conjugated to alkaline phosphatase, the blot was developed using the BCIP/NBT chromogenic substrate solution (SurModics, Eden Prairie, USA) as specified by the manufacturer. The quantification of band intensity was carried out using the densitometry software (Total Lab 1.01; Nonlinear Dynamics Ltd.).

$\mathrm{PLA}_{2}$ activity was measured using the $\mathrm{PLA}_{2}$ Assay Kit (Cayman Chemical, USA) according to the manufacturer's instructions. The absorbance change at $37^{\circ} \mathrm{C}$ and $414 \mathrm{~nm}$ of wavelength was monitored by a spectrophotometer (OPTIZEN POP, Mecasys, Korea) after addition of enzyme solution. One unit (U) of PLA 2 activity was defined as the amount of $\mathrm{PLA}_{2}$ able to hydrolyze $1 \mu \mathrm{mol}$ of diheptanoyl thio-phosphatidylcholine in one minute.

\section{Biotransformation of Soybean Lecithin}

The $10 \mathrm{ml}$ of reaction mixture was formulated with $0.5 \mathrm{mM}$ Tris- $\mathrm{HCl}, 6 \mathrm{mM} \mathrm{CaCl}, 31.1 \mathrm{~g} / \mathrm{l}$ crude soybean lecithin (Sigma-Aldrich, catalog number P3644) ( $\mathrm{pH} \mathrm{8.0),} \mathrm{and} 10 \%(\mathrm{v} / \mathrm{v})$ of enzyme solution. The reaction conditions of $37^{\circ} \mathrm{C}$ and $400 \mathrm{rpm}$ were maintained using a stirring heating mantle (LKLAB KOREA, Korea). According to the manufacturer's information, soybean lecithin consists of an average of $55 \%(42-63 \%) \mathrm{L}-\alpha$ phosphatidylcholine and 20\% (10-32\%) phosphatidylethanolamine. Concentrations of fatty acids were determined by gas chromatography/mass spectrophotometry (GC/MS), as previously reported [20-22]. Fatty acids present in $500 \mu \mathrm{l}$ of samples were extracted by mixing with $2 \mathrm{ml}$ of isopropyl alcohol, $500 \mu \mathrm{l}$ of heptane, and $50 \mu \mathrm{l}$ of sulfuric acid. For the derivatization, $25 \mu \mathrm{l}$ of $\mathrm{N}$-methyl- $N$-(trimethylsilyl)trifluoroacetamide (TMS) (TCI Chemicals, Tokyo, Japan) dissolved in $75 \mu$ of pyridine was added to $60 \mu \mathrm{l}$ of sample solution containing lauric acid (TCI Chemicals) as the internal standard. Concentrations of TMS derivatives were determined using GC/MS (Agilent Technologies, USA) equipped with a flame ionization detector, split injection system, and nonpolar capillary column ( $30 \mathrm{~m}$ length, $0.25 \mathrm{~mm}$ film thickness, HP-5MS, Agilent Technologies). Column temperature was controlled by the following gradient program: $235^{\circ} \mathrm{C}$ for $3 \mathrm{~min}$; increase at a rate of $25^{\circ} \mathrm{C} / \mathrm{min} ; 270^{\circ} \mathrm{C}$ for 10 $\mathrm{min}$; increase at a rate of $5^{\circ} \mathrm{C} / \mathrm{min} ; 300^{\circ} \mathrm{C}$ for $1 \mathrm{~min}$. Mass spectra and scan spectra were obtained by electron impact ionization at $70 \mathrm{eV}$ and within the range of $100-600 \mathrm{~m} / \mathrm{z}$, respectively. Selected ion monitoring was used for the detection and fragmentation analysis of the reaction products.

\section{Results and Discussion}

\section{Production of $\mathrm{PLA}_{2}$ in $P$. pastoris $\mathrm{X}-33$}

To construct expression plasmid for the PLA $\mathrm{A}_{2}$ from $S$. violaceoruber in $P$. pastoris X-33, the codon-optimized $\mathrm{PLA}_{2}$ gene without its native signal sequence was cloned into $\mathrm{PMFa}-\mathrm{PLA}_{2}$ vector under the transcriptional control of the alcohol oxidase 1 (AOX1) gene promoter [23] containing a signal sequence of $S$. cerevisiae mating factor $\alpha$ $(\mathrm{MF} \alpha)$ [24]. A schematic diagram for the $\mathrm{PLA}_{2}$ expression cassette in PPICZaA plasmid and its name are displayed in Fig. 1. We noted that recombinant $\mathrm{PLA}_{2}$ expressed previously in P. pastoris $\left(\mathrm{PLA}_{2}-\mathrm{Pp}\right)$ was designed to contain a part of its native signal sequences (Ala-Pro-Pro-Gln-Ala) [17] whereas these five amino acids are not present in the authentic mature $\mathrm{PLA}_{2}$ and recombinant $\mathrm{PLA}_{2}$ produced in other previous studies $\left(\mathrm{PLA}_{2}-\mathrm{Ec}\right)$, which employed $E$. coli as a host strain (Fig. S2) $[16,18,25]$. In addition to the presence of native signal sequences, amino acid sequences of the $\mathrm{PLA}_{2}$-Pp were not identical (Fig. S2) to those of the $\mathrm{PLA}_{2}$-Ec because these two PLA $\mathrm{P}_{2}$ sere originated from different $S$. violaceoruber sources: the $\mathrm{PLA}_{2}-\mathrm{Pp}$ was from S. violaceoruber 2917 whereas the $\mathrm{PLA}_{2}$ Ec was from S. violaceoruber A-2688. The presence of additional five amino acids at the N-terminal end of $\mathrm{PLA}_{2}{ }^{-}$ Pp resulted in a lower optimum $\mathrm{pH}$ of 6.0 [17] compared to the $\mathrm{PLA}_{2}$-Ec, which has optimum $\mathrm{pH}$ of 7.3-8.3. In addition to optimum $\mathrm{pH}$, this factor might alter the expression level and some properties of the enzyme as reported for lipase B from Candida antarctica (CalB) [26]. Therefore, the $\mathrm{PLA}_{2}$-Ec, which does not have its native signal peptide, was used in this study for accurate comparison of $\mathrm{PLA}_{2}$ production in P. pastoris and E. coli.

As expected, growth of the control strain containing the empty plasmid (pPICZaA) and the P. pastoris X-33 harboring pMFa-PLA 2 was virtually identical regardless of methanol concentrations (Fig. 2A), indicating that expression of $\mathrm{PLA}_{2}$ in P. pastoris had no obvious detrimental effect on growth in general. A batch fermentation of the $P$. pastoris X-33 harboring pMFa-PLA $\mathrm{A}_{2}$ with intermittent addition of $1.0 \%$ methanol led to an extracellular production of $\mathrm{PLA}_{2}$-Ec to an activity of $0.517 \pm 0.012 \mathrm{U} / \mathrm{ml}$ in $120 \mathrm{~h}$ (Fig. $2 \mathrm{~B}$ ) (see the Materials and Methods for the activity assay). This value is much lower than the corresponding value $(34.7 \mathrm{U} / \mathrm{ml})$ obtained by a batch fermentation of $P$. pastoris overexpressing the $\mathrm{PLA}_{2}-\mathrm{Pp}[17]$. This is likely due to the difference of $\mathrm{PLA}_{2}$ sequences and activity assay methods. While the extracellular $\mathrm{PLA}_{2}$ activity with addition of $0.5 \%$ methanol was similar to that with $1.0 \%$ methanol, addition of $1.0 \%$ methanol shortened overall fermentation time from $144 \mathrm{~h}$ to $120 \mathrm{~h}$. 

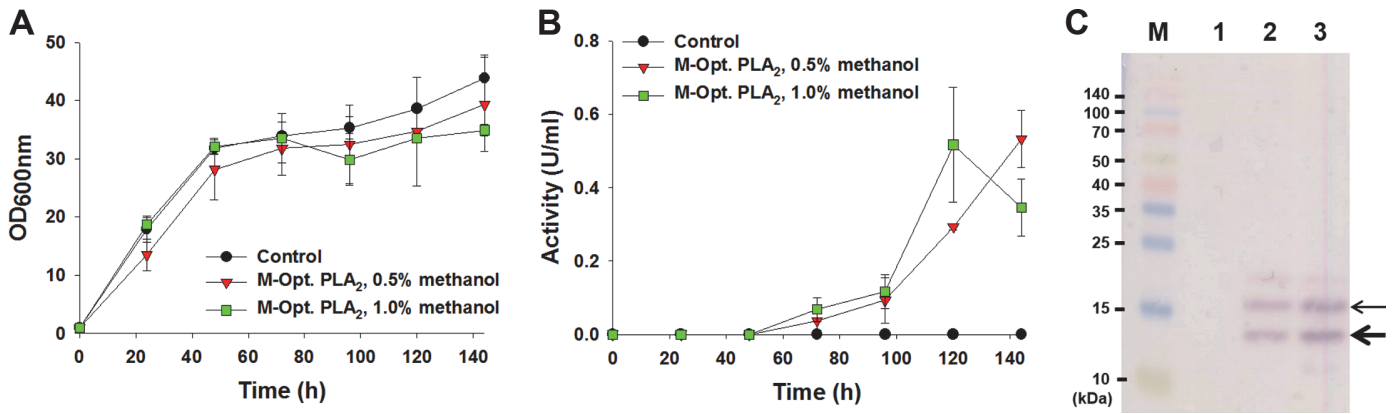

Fig. 2. Batch production of PLA in recombinant $P$. pastoris. (A and $\mathbf{B})$ growth curves $(\mathbf{A})$ and extracellular $\mathrm{PLA}_{2}$ activities (B) of $P$. pastoris X-33 harboring pPICZaA (Control) and pMFa-PLA ${ }_{2}$. Batch production of $\mathrm{PLA}_{2}$ was induced in duplicate by adding $0.5 \%(\mathrm{v} / \mathrm{w})$ or $1.0 \%$ methanol every $24 \mathrm{~h}$. The activities of crude PLA $_{2} \mathrm{~s}$ in the extracellular fraction were measured in triplicate using diheptanoyl thio-phosphatidylcholine as a substrate. (C) Western blotting for His-tagged PLA from the extracellular fraction of the recombinant $P$. pastoris strains. Lanes: M, prestained SDS-PAGE standards; 1 , the control strain; 2, P. pastoris X-33 harboring pMF $\alpha-\mathrm{PLA}_{2}$ induced with $0.5 \%$ methanol; 2, P. pastoris X-33 harboring pMFa-PLA induced with $1.0 \%$ methanol. The thin and thick arrows point to the protein bands of $\mathrm{PLA}_{2}$ with and without glycosylation, respectively.

Although $\mathrm{PLA}_{2}$ was difficult to identify using Coomassie blue staining, it was clearly detected by western hybridization analysis using monoclonal anti-His antibodies (Fig. 2C). A band corresponding to the $14 \mathrm{kDa}$ predicted molecular mass of $\mathrm{PLA}_{2}$ was visible in both $0.5 \%$ and $1.0 \%$ methanol induction conditions. A protein band of approximate molecular mass of $16 \mathrm{kDa}$ was also detected (Fig. 2B), and we speculated that this protein band corresponds to glycosylated PLA $\mathrm{P}_{2}$. This result is consistent with a previous study showing that a part of PLA expressed in P. pastoris was glycosylated as it has three putative glycosylation sites [17].

\section{Production of PLA $\mathrm{A}_{2}$ in Various E. coli Strains}

The authentic PLA 2 gene contains several rare codons for E. coli including Leu (CTC). This codon bias problem could be solved by codon optimization of the gene or by supplying rare-codon tRNAs. Here, we investigated effects of codon optimization of PLA 2 gene on its expression and secretion. The PLA gene expression system was constructed with and without the PelB signal sequence (Fig. 1), which is involved in targeting the proteins to the periplasmic space $[27,28]$. As expected, the $\mathrm{PLA}_{2}$ without the signal sequence showed a basal level of lipase activity in both intracellular and extracellular fractions (Fig. 3A). On the other hand, the lipase activities increased up to $9.4 \pm 1.5 \mathrm{U} / \mathrm{ml}$ in the intracellular fraction and $16.1 \pm 0.9 \mathrm{U} / \mathrm{ml}$ in the culture broth of the recombinant $E$. coli BL21 star (DE3) overexpressing the authentic $\mathrm{PLA}_{2}$ gene $\left(\mathrm{P}-\mathrm{PLA}_{2}\right)$. This is 6.3- and 4.8-times higher than the corresponding values of the case of codon-optimized $\mathrm{PLA}_{2}$ (P-Opt. PLA $\mathrm{P}_{2}$ (Fig. 3A). In addition to the enzyme activity assay, SDS-PAGE analysis showed the high secretion of P-PLA 2 in the culture medium (Fig. S3). This study and earlier studies $[29,30]$ suggest that a faster expression from the optimized gene could lead to higher concentration of target protein, which in turn results in degradation and/or misfolding of the protein.

Protein expression in E. coli BL21 (DE3), BL21 RIL (DE3), BL21 star (DE3), Origami 2 (DE3), C41 (DE3), and C43 (DE3) were analyzed by SDS-PAGE to select a host for PLA $\mathrm{P}_{2}$ production. The expression level of PLA $\mathrm{A}_{2}$ was the highest in E. coli BL21 star (DE3) which has a mutation in the gene encoding RNaseE (rne131 mutation), indicating that protection of mRNAs from RNases plays an important role in $\mathrm{PLA}_{2}$ expression (Fig. S4). Therefore, the highest activities in both intracellular and extracellular fractions were obtained for recombinant $E$. coli BL21 star (DE3) overexpressing P-PLA 2 (Fig. 3B). PLA 2 activities in culture broth of E. coli BL21 (DE3) and BL21 RIL

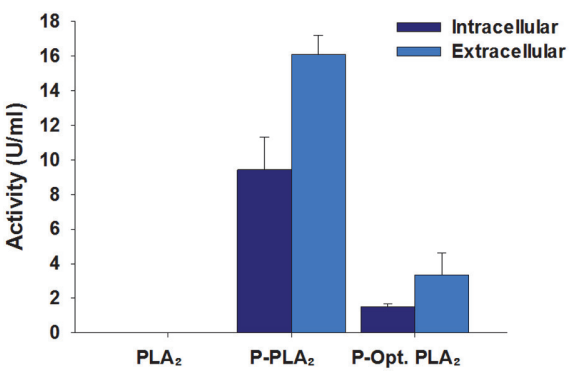

B

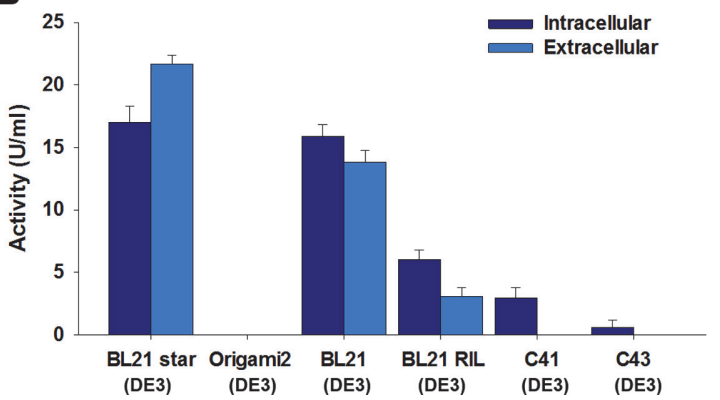

Fig. 3. Effects of codon optimization (A) and E. coli host strains (B) on activities of recombinant PLA in intracellular and extracellular fractions. The activities of crude $\mathrm{PLA}_{2} \mathrm{~s}$ in the soluble and extracellular fractions (see the Materials and Methods for details) collected $24 \mathrm{~h}$ after IPTG induction were measured in triplicate using diheptanoyl thiophosphatidylcholine as a substrate. 


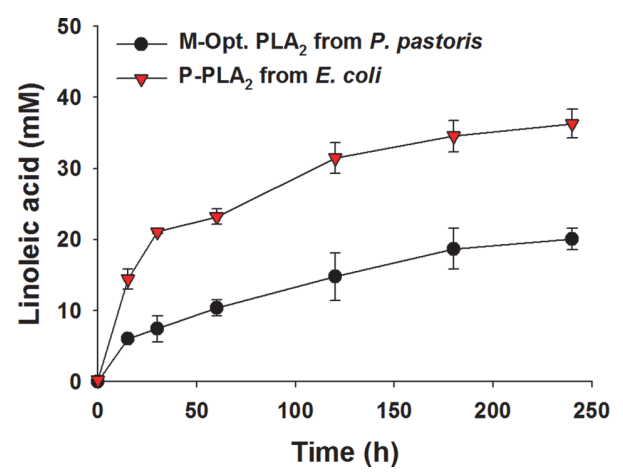

Fig. 4. Biotransformation of crude soybean lecithin into linoleic acid and lysolecithin by recombinant PLA collected from recombinant $P$. pastoris X-33 and E. coli BL21 star (DE3) overexpressing PLA 2 . Biotransformation was initiated by adding 10 -fold concentrated extracellular crude enzyme solutions from the recombinant $P$. pastoris $\mathrm{X}-33$ and $E$. coli BL21 star (DE3) to the reaction mixture consisting of $0.5 \mathrm{mM}$ Tris- $\mathrm{HCl}, 6 \mathrm{mM} \mathrm{CaCl}_{2}$, and $31.1 \mathrm{~g} / \mathrm{l} \mathrm{crude}$ soybean lecithin ( $\mathrm{pH} 8.0)$. Results are the mean of triplicate experiments and error bars indicate standard deviations.

(DE3) exhibited 63.6 and 14.3\% of extracellular activity in E. coli BL21 star (DE3). Thus, E. coli BL21 star (DE3) strain was chosen as the host of PLA $_{2}$ production.

We concluded from these data that alleviating codon bias by codon optimizing the $\mathrm{PLA}_{2}$ gene or by supplying rare-codon tRNAs has negative effects on correct folding of $\mathrm{PLA}_{2}$. This conclusion supports the hypothesis that the translation is a bottleneck in functional expression of $\mathrm{PLA}_{2}$, and hence an overall delay in PLA ${ }_{2}$ expression gives protein machineries more time to fold $\mathrm{PLA}_{2}$ correctly.

Hydrolysis of Soybean Lecithin by Extracellular $\mathrm{PLA}_{2} \mathrm{~s}$ from the Recombinant E. coli and P. pastoris

The extracellular $\mathrm{PLA}_{2}$ activities of the recombinant E. coli $\mathrm{P}_{-} \mathrm{PLA}_{2}$ and P. pastoris X-33 M-Opt. PLA $\mathrm{A}_{2}$ were examined by using an industrial substrate (i.e., crude soybean lecithin). When the extracellular fraction of $P$. pastoris X-33 M-Opt. $\mathrm{PLA}_{2}$ culture (shown in Fig. 2B) was added into the reaction medium containing $31.1 \mathrm{~g} / \mathrm{l}$ of crude soybean lecithin (see the Materials and Methods for details), linoleic acid, which was the major fatty acid constituent of soybean lecithin, was produced to $20.1 \mathrm{mM}$ at $\mathrm{t}=240 \mathrm{~min}$ (Fig. 4). This indicated that approximately $70 \%$ of soybean lecithin was hydrolyzed into lysolecithin and linoleic acid. The extracellular fraction of E. coli P-PLA ${ }_{2}$ culture displayed a biotransformation profile similar to that of P. pastoris X-33 M-Opt. $\mathrm{PLA}_{2}$ culture (Fig. 4). Remarkably, linoleic acid was produced to $36.3 \mathrm{mM}$ at $\mathrm{t}=240 \mathrm{~min}$ (Fig. 4). This indicated that approximately $95 \%$ of soybean lecithin was converted into lysolecithin and linoleic acid. Moreover, the initial conversion rate was 2.6-fold greater than that of P. pastoris X-33 M-Opt. $\mathrm{PLA}_{2}$ culture. Besides, the cultivation time of E. coli P-PLA ${ }_{2}$ was significantly shorter than that of P. pastoris X-33 M-Opt. PLA ( $_{2} 32 \mathrm{~h}$ vs. $120 \mathrm{~h}$ ). It was thereby assumed that the E. coli-based PLA $\mathrm{P}_{2}$ expression system would be superior to the P. pastoris system in terms of extracellular PLA 2 productivity.

Effects of N-terminal Repeat of Aspartate Residues on Specific Activity and Expression of PLA

We previously reported that fusion tag systems composed of the PelB signal sequence and repeated aspartate tags improved both expression and secretion of CalB and asparaginase isozyme II (AnsB) from E. coli [31, 32]. To investigate whether or not repeated aspartate residues would improve the secretion and activity of PLA ${ }_{2}$, various lengths of aspartate residues were introduced into the $\mathrm{N}$-terminal end of $\mathrm{PLA}_{2}$ gene to construct the cassettes $\mathrm{P}$ -

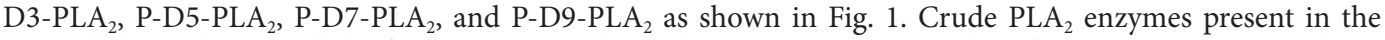
intracellular and extracellular fractions were subjected to SDS-PAGE (Fig. S5) and activity (Fig. 5A) analyses.
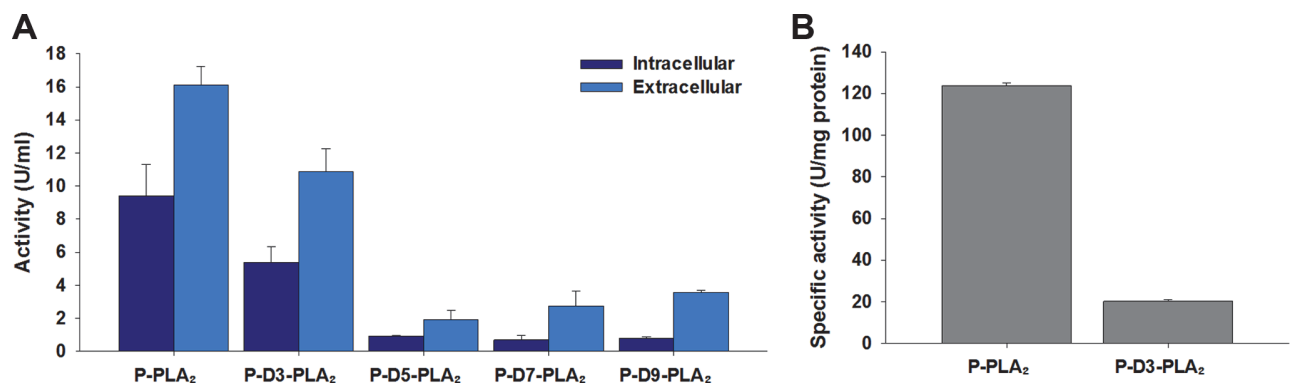

Fig. 5. Activity assays of recombinant $P L A_{2} s$ with various lengths of aspartate tags $(A)$ and His-tag purified P-PLA $_{2}$ and P-D3-PLA 2 (B) to investigate the effects of aspartate tags on expression in E. coli and specific activity of PLA $\mathbf{P}_{2}$. Results are the mean of triplicate experiments and error bars indicate standard deviations. 
Among a series of repeated amino acids consisting of 3,5, 7, or 9 aspartates, the three aspartates facilitated the secretion of $\mathrm{PLA}_{2}$ and hence comparison of the band intensities from the extracellular fractions showed that the

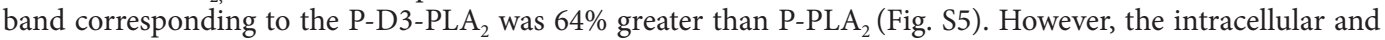
extracellular lipase activities obtained for recombinant $E$. coli BL21 star (DE3) overexpressing P-D3-PLA were $_{2}$ instead $42.6 \%$ and $32.3 \%$ lower than the corresponding values obtained in the case of P-PLA (Fig. 5A). These results suggested that the presence of three aspartate residues at the $\mathrm{N}$-terminal end of $\mathrm{PLA}_{2}$ might alter the specific activity of $\mathrm{PLA}_{2}$. To confirm the hypothesis, $\mathrm{PLA}_{2}$ and P-D3-PLA ${ }_{2}$ were His-tag purified and subjected to activity assay. As expected, specific activity of P-D3-PLA ${ }_{2}$ was 6.1 times lower than that of PLA (Fig. 5B). This result is consistent with previous studies reporting that the attachment of repeated aspartates altered catalytic efficiency of CalB and $\alpha-1,2$-fucosyltransferase (FucT2) from Helicobacter pylori [31,33]. More research is in progress to find $\mathrm{PLA}_{2}$ from other bacteria with increased stability, of which specific activity is not affected significantly by the attachment of repeated aspartates.

In conclusion, this study demonstrated that an E. coli-based PLA ${ }_{2}$ production system could be more efficient in terms of $\mathrm{PLA}_{2}$ productivity, as compared to the P. pastoris-based system. Among the E. coli host strains harboring the authentic PLA 2 gene $\left(\mathrm{P}_{-} \mathrm{PLA}_{2}\right.$ ) or codon- optimized PLA (P-Opt. PLA $_{2}$ ), the recombinant E. coli BL21 star (DE3) $\mathrm{P}-\mathrm{PLA}_{2}$ has exhibited the highest activities of $21.7 \pm 0.7 \mathrm{U} / \mathrm{ml}$ in the culture broth and $17.0 \pm 1.3 \mathrm{U} / \mathrm{ml}$ in the intracellular fraction. Moreover, the extracellular $\mathrm{PLA}_{2} \mathrm{~S}$ from the recombinant E. coli P-PLA ${ }_{2}$ culture was able to hydrolyze $31.1 \mathrm{~g} / \mathrm{l}$ of crude soybean lecithin to linoleic acid and lysolecithin at a conversion yield of at least $95 \%$. Therefore, it was concluded that the recombinant $E$. coli $\mathrm{P}_{-} \mathrm{PLA}_{2}$ system could be used as a microbial cell factory to produce a catalytically active PLA 2 for hydrolysis of the selective sn-2 position of plant lecithins.

\section{Acknowledgments}

This research was financially supported by the National Research Foundation of Korea (NRF) Grant (2019R1C1C1003521) funded by the Korean Ministry of Science, ICT and Future Planning, and also by the Chung-Ang University Graduate Research Scholarship in 2019. Ara Cho, Yeji Hwang, and Jin-Byung Park were supported by the Marine Biomaterials Research Center grant from the Marine Biotechnology Program [No. D11013214H480000100] funded by the Ministry of Oceans and Fisheries, Korea.

\section{Conflict of Interest}

The authors have no financial conflicts of interest to declare.

\section{References}

1. Cerminati S, Paoletti L, Aguirre A, Peiru S, Menzella HG, Castelli ME. 2019. Industrial uses of phospholipases: current state and future applications. Appl. Microbiol. Biotechnol. 103: 2571-2582.

2. De Maria L, Vind J, Oxenboll KM, Svendsen A, Patkar S. 2007. Phospholipases and their industrial applications. Appl. Microbiol. Biotechnol. 74: 290-300.

3. Dijkstra AJ. 2010. Enzymatic degumming. Eur. J. Lipid Sci. Technol. 112: 1178-1189.

4. Noel JP, Tsai MD. 1989. Phospholipase $\mathrm{A}_{2}$ engineering: design, synthesis, and expression of a gene for bovine (pro)phospholipase $\mathrm{A}_{2}$. J. Cell Biochem. 40: 309-320.

5. van den Bergh CJ, Bekkers AC, De Geus P, Verheij HM, de Haas GH. 1987. Secretion of biologically active porcine prophospholipase $\mathrm{A}_{2}$ by Saccharomyces cerevisia: use of the prepro sequence of the alpha-mating factor. Eur. J. Biochem. 170: 241-246.

6. Lefkowitz LJ, Deems RA, Dennis EA. 1999. Expression of group IA phospholipase $\mathrm{A}_{2}$ in Pichia pastoris: identification of a phosphatidylcholine activator site using site-directed mutagenesis. Biochemistry 38: 14174-14184.

7. Liu YH, Huang L, Li MJ, Liu H, Guo W, Gui S, et al. 2016. Characterization of the recombinant porcine pancreas phospholipase $\mathrm{A}_{2}$ expressed in Pichia pastoris GS115 and its application to synthesis of 2-DHA-PS. Process Biochem. 51: 1472-1478.

8. Roberts IN, Jeenes DJ, MacKenzie DA, Wilkinson AP, Sumner IG, Archer DB. 1992. Heterologous gene expression in Aspergillus niger: a glucoamylase-porcine pancreatic prophospholipase $\mathrm{A}_{2}$ fusion protein is secreted and processed to yield mature enzyme. Gene 122: 155-161.

9. Markert Y, Mansfeld J, Schierhorn A, Rucknagel KP, Ulbrich-Hofmann R. 2007. Production of synthetically phospholipase $\mathrm{A}_{2}$ variants created with industrial impact. Biotechnol. Bioeng. 98: 48-59.

10. Lathrop BK, Burack WR, Biltonen RL, Rule GS. 1992. Expression of a group II phospholipase $\mathrm{A}_{2}$ from the venom of Agkistrodon piscivorus piscivorus in Escherichia coli: recovery and renaturation from bacterial inclusion bodies. Protein Expr. Purif. 3: 512-517.

11. Giuliani CD, Iemma MR, Bondioli AC, Souza DH, Ferreira LL, Amaral AC, et al. 2001. Expression of an active recombinant lysine 49 phospholipase A myotoxin as a fusion protein in bacteria. Toxicon 39: 1595-1600.

12. Yang WL, Peng LS, Zhong XF, Wei JW, Jiang XY, Ye LT, et al. 2003. Functional expression and characterization of a recombinant phospholipase $\mathrm{A}_{2}$ from sea snake Lapemis hardwickii as a soluble protein in E. coli. Toxicon 41: 713-721.

13. Jin Q, Yang LX, Jiao HM, Lu B, Wu YQ, Zhou YC. 2004. Purification, gene cloning and expression of an acidic phospholipase $\mathrm{A}_{2}$ from Agkistrodon shedaoensis Zhao. Acta Biochim. Biophys. Sin. 36: 27-32.

14. Esposito D, Chatterjee DK. 2006. Enhancement of soluble protein expression through the use of fusion tags. Curr. Opin. Biotechnol. 17:353-358.

15. Dennis EA, Cao J, Hsu YH, Magrioti V, Kokotos G. 2011. Phospholipase $A_{2}$ enzymes: physical structure, biological function, sisease implication, chemical inhibition, and therapeutic intervention. Chem. Rev. 111: 6130-6185.

16. Sugiyama M, Ohtani K, Izuhara M, Koike T, Suzuki K, Imamura S, et al. 2002. A novel prokaryotic phospholipase $A_{2}$ : characterization, gene cloning, and solution structure. J. Biol. Chem. 277: 20051-20058.

17. Liu AX, Yu XW, Sha C, Xu Y. 2015. Streptomyces violaceoruber phospholipase $\mathrm{A}_{2}$ : expression in Pichia pastoris, properties, and application in oil degumming. Appl. Biochem. Biotechnol. 175: 3195-3206.

18. Takemori D, Yoshino K, Eba C, Nakano H, Iwasaki Y. 2012. Extracellular production of phospholipase A from Streptomyces violaceoruber by recombinant Escherichia coli. Protein Expres. Purif. 81: 145-150.

19. Jung H-J, Kim S-K, Min W-K, Lee S-S, Park K, Park Y-C, et al. 2011. Polycationic amino acid tags enhance soluble expression of Candida antarctica lipase B in recombinant Escherichia coli. Bioprocess Biosyst. Eng. 34: 833-839. 
20. Jeon E-Y, Seo J-H, Kang W-R, Kim M-J, Lee J-H, Oh D-K, et al. 2016. Simultaneous enzyme/whole-cell biotransformation of plant oils into C9 carboxylic acids. ACS Catal. 6: 7547-7553.

21. Seo E-J, Yeon YJ, Seo J-H, Lee J-H, Boñgol JP, Oh Y, et al. 2018. Enzyme/whole-cell biotransformation of plant oils, yeast derived oils, and microalgae fatty acid methyl esters into $n$-nonanoic acid, 9-hydroxynonanoic acid, and 1,9-nonanedioic acid. Bioresour. Technol. 251: 288-294.

22. Seo E-J, Kim H-J, Kim M-J, Kim J-S, Park J-B. 2019. Cofactor specificity engineering of a long-chain secondary alcohol dehydrogenase from Micrococcus luteus for redox-neutral biotransformation of fatty acids. Chem. Comm. 55: 14462-14465.

23. Tschopp JF, Brust PF, Cregg JM, Stillman CA, Gingeras TR. 1987. Expression of the lacZ gene from two methanol-regulated promoters in Pichia pastoris. Nucleic Acids Res. 15: 3859-3876.

24. Brake AJ, Merryweather JP, Coit DG, Heberlein UA, Masiarz FR, Mullenbach GT, et al. 1984. Alpha-factor-directed synthesis and secretion of mature foreign proteins in Saccharomyces cerevisiae. Proc. Natl. Acad. Sci. USA 81: 4642-4646.

25. Matoba Y, Sugiyama M. 2003. Atomic resolution structure of prokaryotic phospholipase $A_{2}$ : analysis of internal motion and implication for a catalytic mechanism. Proteins 51: 453-469.

26. Blank K, Morfill J, Gumpp H, Gaub HE. 2006. Functional expression of Candida antarctica lipase B in Eschericha coli. J. Biotechnol. 125: $474-483$

27. Jung SM, Seo JH, Lee JH, Park JB, Seo JH. 2015. Fatty acid hydration activity of a recombinant Escherichia coli-based biocatalyst is improved through targeting the oleate hydratase into the periplasm. Biotechnol. J. 10: 1887-1893.

28. Jeon EY, Song JW, Cha HJ, Lee SM, Lee J, Park JB. 2018. Intracellular transformation rates of fatty acids are influenced by expression of the fatty acid transporter FadL in Escherichia coli cell membrane. J. Biotechnol. 281: 161-167.

29. Liu D, Schmid RD, Rusnak M. 2006. Functional expression of Candida antarctica lipase B in the Escherichia coli cytoplasm: a screening system for a frequently used biocatalyst. Appl. Microbiol. Biotechnol. 72: 1024-1032.

30. Jung SY, Park SS. 2008. Improving the expression yield of Candida antarctica lipase B in Escherichia coli by mutagenesis. Biotechnol. Lett. 30: 717-722.

31. Kim SK, Park YC, Lee HH, Jeon ST, Min WK, Seo JH. 2015. Simple amino acid tags improve both expression and secretion of Candida antarctica lipase B in recombinant Escherichia coli. Biotechnol. Bioeng. 112: 346-355.

32. Kim SK, Min WK, Park YC, Seo JH. 2015. Application of repeated aspartate tags to improving extracellular production of Escherichia coli L-asparaginase isozyme II. Enzyme Microb. Technol. 79-80: 49-54.

33. Chin YW, Kim JY, Lee WH, Seo JH. 2015. Enhanced production of 2 '-fucosyllactose in engineered Escherichia coli BL21star(DE3) by modulation of lactose metabolism and fucosyltransferase. J. Biotechnol. 210: 107-115. 